\title{
DO VIVIDO AO REDIGIDO: OS ILETRADOS E A ESCRITA
}

\author{
Lived to the states: the illiterate and writing
}

\author{
Sílvia Maria Amâncio Rachi Vartuli*
}

\begin{abstract}
RESUMO
Este texto é um recorte da pesquisa de doutorado, desenvolvida na Faculdade de Educação da UFMG, por meio da qual investigamos os usos sociais da escrita feitos por mulheres em Minas Gerais no período de 1780 a 1822. O corpus documental selecionado apresenta como principais fontes os testamentos post mortem das duas últimas décadas do século XVIII até 1822, pertencentes ao acervo do Arquivo do Museu do Ouro/Instituto Brasileiro de Museus (IBRAM), em Sabará, referentes ao território da Comarca do Rio das Velhas. Partimos da convicção de que as relações com a escrita ultrapassam em muito a capacidade de redigir de "próprio punho". Começamos a nos mover, assim, com o inquietante objetivo de tornar clara a pragmática da constituição do escrito, não o subordinando apenas à redação autônoma. Para nortear-nos na análise das fontes, pautamo-nos nos autores dedicados à compreensão dos fenômenos da alfabetização e letramento, bem como em reflexões de pesquisadores que investigaram esses fenômenos em perspectiva histórica e de autores referenciais no estudo da sociedade do nosso período colonial. Aqui, tecemos breve discussão historiográfica acerca da cultura escrita e das práticas educativas na sociedade colonial e explicitamos algumas das análises desenvolvidas durante a investigação. Ativemo-nos ao processo de constituição do texto testamental e à observação das elaborações discursivas dos sujeitos. Embasados na literatura voltada a destacar o papel da oralidade na autoria dos textos, tornou-se possível perceber como diferentes mulheres, inclusivamente as não alfabetizadas, foram capazes de elaborar e redigir textos, ainda que por mãos alheias, e, dessa forma, utilizarem-se da escrita.
\end{abstract}

Palavras-chave: Minas Gerais colonial; cultura escrita; escrita-Antigo Regime.

(PUC-Minas).

Professora - Departamento de História. Pontifícia Universidade Católica de Minas Gerais 


\begin{abstract}
This article is part of a research doctorate, developed at the Faculty of Education, UFMG, where we investigated the social uses of writing by women in Minas Gerais in the period 1780-1822. The corpus of analysis selected has as main documents wills of the territory of Rio das Velhas District from the referred period which belongs to the Archives of the Institute of Gold / Brazilian Museums (IBRAM)/House Borba Gato in Sabará. We share the conviction that relationships with writing go far beyond the ability to write with your "own hands". Our objective was to make visible the pragmatics of the writing and not what was related to the writing skills. In this sense, we aimed to disengage from the conception that associates the relationships with the writing with a rigid architecture of communication systems to understand them in an open, versatile and creative space. Our analyses were drawn by three sets of theoretical frameworks. Firstly, we based on authors who searched to understand the phenomena of literacy as well as on reflections of researchers who investigated the same phenomenon in a historical perspective. Secondly, we were supported by studies about the colonial period of our society. Supported by literature that highlights the role of orality in written texts, it became possible to see how different women, especially those who could not read or write, were able to develop and write texts, even by the hands of others and thus use the writing.
\end{abstract}

Keywords: writing; writing culture; colonial Minas Gerais.

\title{
1. A cultura escrita no Antigo Regime: breve discussão historiográfica
}

Às últimas páginas dos livros têm sido destinadas as reflexões sobre as posições ocupadas por iletrados, analfabetos ou não assinantes nas sociedades caracterizadas pelas práticas de escrita. Marcadas pelo silêncio historiográfico, tais posições, quando se referem especificamente ao "ato de escrever", não foram, ainda, consideradas de maneira detida pelos pesquisadores. ${ }^{1}$ Normalmente,

1 Ressalvem-se sobre este aspecto alguns trabalhos: MAGALHÃES, Justino Pereira de. Ler e escrever no mundo rural do Antigo Regime: um contributo para a história da alfabetização e da escolarização em Portugal. Braga: Universidade do Minho, 1994; e MARQUILHAS, Rita. A faculdade das letras: leitura e escrita em Portugal no século XVII. Lisboa: Imprensa Nacional/Casa da Moeda, 2000; e, especificamente 
as investigações reafirmam o lugar secundarizado atribuído a esses agentes em suas relações com a escrita. Nesse quadro, as mulheres são correntemente qualificadas como "analfabetas", "não assinantes", "possuidoras de níveis inferiores de alfabetização ou de letramento", sem que esses qualitativos sejam problematizados e compreendidos em sua multifacetação e sem que outras formas de vinculação com a ação de escrever sejam consideradas.

Este artigo configura-se como recorte da pesquisa de doutorado, desenvolvida na Faculdade de Educação da Universidade Federal de Minas Gerais $^{2}$, em que buscamos demonstrar os usos sociais da escrita na Minas Gerais colonial $^{3}$. Aqui tentamos realizar uma breve discussão historiográfica a respeito da abordagem dos fenômenos relacionados à cultura escrita e às práticas educativas na sociedade mineira colonial, em particular à educação feminina. Em seguida explicitamos, também, parte das análises desenvolvidas durante a investigação.

Intencionamos em nossa pesquisa resgatar escritas que emergiram das falas de sujeitos comuns, numa abordagem que, se não completamente esquecida pela historiografia, parece repousar à sombra da tendência em se analisar os papéis desempenhados pelas elites, autoridades, funcionários régios, ou seja, por protagonistas letrados pertencentes ou vinculados diretamente às redes de poder.

para a América portuguesa, possuindo como recorte espacial a comarca do Rio das Mortes, ver: MORAIS, Christianni Cardoso. Posses e usos da cultura escrita e difusão da escola: de Portugal ao Ultramar, Vila e Termo de São João del-Rei, Minas Gerais (1750-1850). 337 f. Tese (Doutorado) - Faculdade de Filosofia e Ciências Humanas, Universidade Federal de Minas Gerais, Belo Horizonte, 2009. Esses pesquisadores abordaram as práticas de letramento das diferentes camadas sociais em sociedades pretéritas. Ainda assim, cabe frisar que, por buscarem apresentar "índices" de alfabetização/letramento, prendem-se ao traço autográfico para a realização de suas investigações. Mesmo existindo, no Brasil, importantes estudos que se dedicaram a evidenciar as práticas de leitura, não conhecemos, pelo levantamento bibliográfico realizado, pesquisas que possuam como foco as relações estabelecidas pelos que "não sabiam escrever" com a escrita no período em pauta.

2 A pesquisa contou com o apoio financeiro da Coordenação de Aperfeiçoamento de Pessoal de Nível Superior (CAPES).

3 Foram levantados, para a pesquisa, 557 testamentos de mulheres registrados nas duas últimas décadas do século XVIII e nas duas primeiras do XIX (até 1822), pertencentes ao acervo do Arquivo do Museu do Ouro/Instituto Brasileiro de Museus (IBRAM)/Casa Borba Gato, em Sabará, Minas Gerais, e que se referem ao antigo território da Comarca do Rio das Velhas. Este número corresponde à consulta a um total de 43 livros de registros. A partir deles, listamos todos os testamentos post mortem de mulheres registrados nesse espaço de tempo. As referências à documentação do acervo desta instituição serão feitas no texto iniciando-se pela sigla $\mathrm{MO} / \mathrm{CBG} / \mathrm{CPO} / \mathrm{LT}$ (Museu do Ouro/Casa Borba Gato/Cartório do $1^{\circ} \mathrm{Ofício/}$ Livro de Testamento), seguida dos números específicos dos livros - cotas atuais e cotas antigas (número entre parênteses) - e das folhas consultadas. 
Em especial, na primeira década do atual século, reabilitaram-se os estudos sobre a administração, a justiça e o exercício do poder na América portuguesa. Afloraram, por decorrência, a importância e o significado das capacidades de ler e escrever, em detrimento das relações estabelecidas com a escrita por setores iletrados da população. Foi este último aspecto que, em realidade específica, tentamos compreender.

Dada a multifacetação e a complexidade do objeto de estudo, usos sociais da escrita, a investigação, ao situar-se nos campos da história da educação e da história da cultura escrita, buscou estabelecer, além do diálogo com parte da historiografia dedicada ao período colonial - destacadamente no que concerne às práticas sociais ligadas ao universo feminino e à circulação da escrita -, interlocuções com outros campos do saber. Dialogamos especialmente com os trabalhos desenvolvidos pela linguística e pela antropologia. De acordo com Peter Burke, nas últimas décadas do século XX emergiu uma história social da linguagem, do falar ou da comunicação, denotando, especialmente para os historiadores, o lugar fundamental da linguagem na vida cotidiana. ${ }^{4}$

Nesse caminho interdisciplinar, é preciso destacar, de igual maneira, a importância das investigações desenvolvidas no campo de estudos história da cultura escrita. Nessa área do conhecimento, os investigadores têm somado esforços e incorporado às suas discussões problemáticas concernentes à história da alfabetização e à história do livro e da leitura, para a abordagem e compreensão dos nexos existentes entre alfabetização e letramento - tendo-se em conta os processos de aquisição das habilidades de ler, escrever e contar - e circulação da palavra escrita e atuação social. De acordo com Antonio Castillo Gómez: "[...] el objetivo de la historia de la cultura escrita pasaría justamente por ensamblar, en una historia de la larga duración, los diferentes suportes del escrito y las diversas prácticas que lo producen o lo apropian." 5 .

Torna-se fundamental, entretanto, entender melhor o que, em alguns momentos, é abordado como conceito e, em outros, como campo de estudos denominado cultura escrita, abarcando, inclusive, pesquisas

4 BURKE, Peter. A arte da conversação. Trad. Alvaro Luiz Hattnher. São Paulo: Ed. Unesp, 1995.

5 CASTILLO GÓMEZ, Antonio. Historia de la cultura escrita: ideas para el debate. Revista Brasileira de História da Educação, Campinas, n. 5, p. 93-124, jan.-jul. 2003. p. 105. 
relativas à alfabetização e ao letramento. Ou seja, sentimos necessidade de compreender os significados assumidos pela expressão cultura escrita, uma vez que, conforme percebemos, pode se tratar de uma abstração - sofrendo transformações de acordo com o contexto estudado -, de produto, artefato histórico - manifesto por meio dos suportes nos quais é veiculado - e, de maneira semelhante, de campo de estudos, como mencionado.

Disso se depreende que a expressão vem sendo utilizada/empregada com diferentes conotações. Na história e na história da educação (haja vista que o objeto escrita é analisado no interior de diferentes disciplinas - a linguística, a comunicação, a história, a antropologia, as artes, a psicologia -, e, por isso, a existência de abordagens conceituais e metodológicas diferenciadas), mais do que buscar definição conceitual para escrita, assaltou-nos a necessidade de compreendermos a "cartografia" dos estudos sobre a temática escrita (apesar de, por vezes, o conjunto de trabalhos referir-se à posse/uso/circulação da cultura letrada). Seja como for, a comunicação escrita tem sido tomada como objeto de estudo por número expressivo de historiadores e de historiadores da educação, voltando-se o interesse desses para a compreensão das apropriações dos elementos da escrita, usos, posses e práticas a ela relacionados.

Buscamos, assim, evidenciar a riqueza do campo com suas diferentes perspectivas de abordagem e, igualmente, exigências de diálogos. Essa intenção nos levou a tentar proceder a uma classificação dos trabalhos analisados. Conseguimos identificar e delimitar, na historiografia, de maneira sumariada, três eixos de investigação, a saber:

1. estudos que traçam uma trajetória histórica e evolutiva da própria linguagem, e, como uma de suas dimensões, a escrita (não necessariamente a alfabética), de orientação histórica, antropológica e/ou etnográfica, contrapondo, por vezes, as sociedades ágrafas às sociedades com escrita, a tradição oral à cultura escrita ${ }^{6}$

2. estudos que buscam conceituar o termo escrita, estabelecer taxas de alfabetização/letramento em períodos e espaços geográficos específicos, bem como evidenciar as decorrências do domínio

6 Por exemplo: os trabalhos de BOUZA ÁLVAREZ, Fernando J. Del escribano a la biblioteca: la civilización escrita europea en la Alta Edad Moderna (siglos XV-XVIII). Madrid: Síntesis, 1992; e de CURTO, Diogo Ramada. Cultura escrita: séculos XV-XVIII. Lisboa: Imprensa de Ciências Sociais, 2007. 
das habilidades de ler e escrever, os caminhos e as estratégias pessoais e/ou familiares para o aprendizado das primeiras letras, além de analisarem envolvimentos diferenciados com o universo escrito no que tange a dimensões da vida privada, ou seja, às práticas individuais de escrita (escrita de livros de razão, cartas, diários etc. $) ;^{7}$

3. investigações respeitantes a diferentes "manifestações letradas", à redação/elaboração, circulação, posse e comercialização de impressos (estudos sobre as bibliotecas particulares), ao universo dos sujeitos letrados (escritores e literatos), à ocorrência e dinâmica das aulas públicas e particulares (em nível elementar e/ou universitário) e à realização de ofícios que demandavam o domínio das habilidades de ler e escrever, além dos trabalhos cujo foco é o uso da escrita nas esferas administrativa e religiosa. ${ }^{8}$

Não objetivamos com isso criar divisões ou classificações rígidas e impermeáveis relativas ao conjunto de investigações. Na verdade, essa "classificação" visa apenas à organização mais didática dos trabalhos encontrados.

Nas últimas décadas, a historiografia tem se mostrado sensível à tentativa de compreensão dos fenômenos relacionados às práticas de leitura e de escrita nos mais variados espaços. A abordagem do campo é de tal ordem vasta que percebemos certa indistinção, traduzida na existência de coletâneas organizadas com temas ligados, de algum modo, à "comunicação/cultura escrita" - que, em certos momentos, como afirmamos, parece

(1994).

7 É o caso, dentre outras, da obra, aqui já referenciada, de Justino Pereira de Magalhães

8 Este terceiro "eixo", em alguns casos, mescla-se ao campo de estudos história do livro e da leitura. A propósito, dentre outros textos, reporte-se à tese de Christianni Cardoso Morais (2009).

9 Tomemos como exemplo o livro organizado por ALGRANTI, Leila Mezan; MEGIANI, Ana Paula Torres (Orgs.). O Império por escrito: formas de transmissão da cultura letrada no mundo Ibérico (séc. XVI-XIX). São Paulo: Alameda, 2009. De acordo com as organizadoras: "Este livro reúne um conjunto de ensaios que procuram destacar a importância e os significados da comunicação escrita no mundo ibérico moderno, em especial no império português. O que pretendemos é despertar e sensibilizar os leitores e leitoras para a relevância da coexistência de diversos circuitos e variados níveis de comunicação nos impérios coloniais da época moderna, presentes tanto no âmbito oficial das relações de poder da monarquia quanto em dimensões coevas ou alternativas a ele. Nesses circuitos, além dos impressos, registros manuscritos de todo tipo (cartas, regulamentos, crônicas, gramáticas) desempenharam um papel fundamental na transmissão de ideias, valores, normas, costumes e saberes entre a metrópole e suas colônias, bem como entre as diferentes possessões ultramarinas que integravam tais impérios coloniais." (p. 9). Entendemos que cultura escrita acolhe a cultura letrada, mas acreditamos que a ela não pode ser reduzida. 
ser utilizada como sinônimo de cultura letrada -, até a de estudos teóricos, dedicados à compreensão e definição do conceito de escrita ou de "cultura escrita" stricto sensu. Ressaltamos o fato de algumas investigações se enquadrarem em mais de um dos eixos apresentados, dada a amplitude do objeto de estudo. ${ }^{10}$ Ademais, nos três eixos mencionados, não é incomum encontrarmos trabalhos direcionados ao entendimento das práticas e dos hábitos de leitura e/ou à vida de leitores e/ou comunidades de leitores, mesclando-se à linha de estudos história do livro e da leitura. ${ }^{11}$

\section{Cultura escrita e práticas educativas na América portuguesa}

No campo da história da educação, a maioria dos estudos existentes, realizados até a década de 1980, respeitantes ao Brasil colonial, apresenta

10 Como exemplo, citemos a pesquisa de Christianni Cardoso Morais, Posse e usos da cultura escrita e difusão da escola: de Portugal ao Ultramar, Vila e Termo de São João del-Rei, Minas Gerais (1750-1850), que se propôs a analisar índices de letramento, isto é, uso e posse da cultura escrita, as bibliotecas particulares, como meio de circulação/posse da escrita, bem como a difusão da escrita a partir dos processos de escolarização. Dada a vastidão do objeto, a referida pesquisa poderia ser "enquadrada" também no primeiro e no segundo eixos de investigação.

11 A esse respeito ver, dentre outros: ALGRANTI, Leila Mezan. Livros de devoção, atos de censura: ensaios de história do livro e da leitura na América portuguesa (1750-1821). São Paulo: Hucitec, 2004; ABREU, Márcia (Org.). Leitura, história e história da leitura. Campinas: Mercado das Letras, 1999; VILLALTA, Luiz Carlos. Reformismo ilustrado, censura e práticas da leitura: usos do livro na América portuguesa. 1999. 442 f. Tese (Doutorado) - Faculdade de Filosofia, Letras e Ciências Humanas, Universidade de São Paulo, São Paulo, 1999; ALGRANTI, Leila Mezan; MEGIANI, Ana Paula Torres (Org.). $O$ Império por escrito: formas de transmissão da cultura letrada no mundo ibérico. São Paulo: Alameda, 2009; ALVARENGA, Thábata Araújo de. Homens e livros em Vila Rica - 1750-1800. 218 f. Dissertação (Mestrado) - Faculdade de Filosofia, Letras e Ciências Humanas, Universidade de São Paulo, São Paulo, 2003. A história do livro e da leitura tem como expoente principal Roger Chartier, que trabalha as relações existentes entre autor, editor, texto e leitor que circunscrevem o texto e a prática de leitura. Chartier discute o conceito de inventividade do leitor. Seus estudos sobre a leitura estão atentos às condições históricas e sociais particulares que forjam modos de ler e usos peculiares da leitura. CHARTIER, Roger. $A$ ordem dos livros: leitores, autores e bibliotecas na Europa entre os séculos XIV e XVIII. Trad. Mary Del Priore. Brasília: Ed. UnB, 1994; CHARTIER, Roger. Práticas da leitura. Trad. Cristiane Nascimento. São Paulo: Estação Liberdade, 1996; CHARTIER, Roger. A aventura do livro: do leitor ao navegador. Trad. Reginaldo de Moraes. São Paulo: Ed. Unesp, 1998; CHARTIER, Roger. Formas e sentido, cultura escrita: entre distinção e apropriação. Trad. Maria de Lourdes Meirelles Matencio. Campinas: ALB/Mercado de Letras, 2003; CHARTIER, Roger. Leituras e leitores na França do Antigo Regime. Trad. Álvaro Lorencini. São Paulo: Ed. Unesp, 2004. 
como ponto central de análise a atuação da Companhia de Jesus e a aplicação das chamadas Reformas Pombalinas, sobretudo a criação e a implantação das aulas régias. A educação, nesse contexto, é abordada em sua dimensão institucional. As referências praticamente se limitam à investigação da atuação jesuítica no campo do ensino até a expulsão dos seus religiosos, a partir de 1759, do território de Minas Gerais pelo futuro Marquês de Pombal, bem como à compreensão das reformas educacionais então processadas. ${ }^{12}$

Acreditamos que o entendimento das práticas educativas no Antigo Regime requer o alargamento da concepção dos atos de ensinar e de aprender naquela realidade. Obriga-nos a considerar diferentes possibilidades de aprendizagem esboçadas fora dos espaços institucionais de educação. Dessa maneira, devemos tentar identificar os espaços, os agentes e os mecanismos que proporcionaram a circulação da escrita, permitindo às mulheres os usos desse conhecimento e, por decorrência, o desenvolvimento de estratégias e de negociações no jogo social.

De acordo com essa ótica, compreendemos as práticas educativas como todo processo em que há a transmissão de conhecimento de diversas origens e características e com diferentes finalidades, independentemente do local onde ocorram. São "maneiras de fazer cotidianas dos sujeitos históricos, relacionadas social e culturalmente, na construção de seus espaços, suas posições e suas identidades" ${ }^{13}$.

No que tange à produção historiográfica sobre o período colonial brasileiro relativa aos fenômenos educativos, é possível afirmar que, em

12 Os trabalhos concentram-se, grosso modo, na reflexão acerca das estruturas e da burocracia escolar. Podemos apontar como representantes dessa vertente historiográfica: José Ricardo Pires de Almeida, Moreira D'Azevedo, Feu de Carvalho, Raul Briquet, Hélio Vianna, Antônio Alberto Banha de Andrade, Fernando de Azevedo e Laerte Ramos de Carvalho. Há de se ressaltar que, para esses autores, os processos educativos não institucionais, leia-se não escolares, situam-se num segundo plano de análise. Com essa mesma característica e mais afinados à tradição historiográfica que ressalta os papéis do Estado e da Igreja, engrandecendo as ações dos jesuítas e tecendo críticas às políticas relativas à educação, encontram-se os estudos de José Ricardo Pires de Almeida, Fernando de Azevedo e Otaíza de Oliveira Romanelli. No contexto das Reformas Pombalinas, no que concerne às análises das características regionais percebidas no processo de concretização das mesmas, destacam-se: José Ferreira Carrato, para a Capitania de Minas Gerais, Tereza Maria Fachada Levy Cardoso, para a realidade do Rio de Janeiro, Myriam Xavier Fragoso, para São Paulo, e, para o Mato Grosso, Gilberto Luiz Alves. Especificamente com relação à análise das aulas régias, em abordagem mais atual, temos os estudos de José Carlos de Araújo Silva, referente à realidade da Bahia, e de Adriana Maria Paulo da Silva, que observa o processo de escolarização entre o final do século XVIII e a primeira metade do século XIX, em Pernambuco.

13 FONSECA, Thais Nívia de Lima e. Letras, oficios e bons costumes: civilidade, ordem e sociabilidades na América portuguesa. Belo Horizonte: Autêntica, 2009. 
grande parte, as pesquisas realizadas preocuparam-se em analisar a implementação e o funcionamento das Reformas Pombalinas no âmbito da educação, as adaptações e os desvios ocorridos nesse processo, além da circulação, usos e posses dos materiais impressos. ${ }^{14}$

No conjunto dessa historiografia, destacamos a existência de estudos cuja natureza do objeto acaba por aproximar a discussão dos processos educativos, apesar de não os terem como foco. Destarte, iluminam os intercâmbios desenrolados entre as mulheres e as dimensões variadas do saber e da cultura. Ao ampliarem o leque de abordagens - dentro do movimento de renovação historiográfica de onde emergem sujeitos até então negligenciados nos processos históricos -, alentadas pesquisas se preocuparam em dar maior visibilidade à mulher, à criança e às relações familiares. ${ }^{15}$

14 No universo dos trabalhos mais recentes, consigne-se a pesquisa de doutorado de Christianni Cardoso Morais (MORAIS, 2009), que, utilizando-se de documentação variada, buscou compreender os usos e a circulação da "cultura escrita", inclusive a partir da expansão da escolarização no período. Deteve-se nas continuidades e rupturas desses processos em Portugal e no Brasil, particularmente na Vila e no Termo de São João del-Rei. A autora inova ao inserir na discussão historiográfica reflexões acerca dos processos de letramento e dos usos da "cultura escrita" por distintas camadas da população.

15 Nessa perspectiva, destacamos as investigações de ALGRANTI, Leila Mezan. Seus trabalhos referem-se às famílias e à vida doméstica na América portuguesa e à condição feminina nos conventos e recolhimentos no Brasil. Em Honradas e devotas: mulheres da Colônia. Rio de Janeiro: José Olympio; Brasília: Ed. UnB, 1993, Algranti ilumina aspectos das vidas das mulheres naquela sociedade e quebra paradigmas com relação à figura feminina, analisa seus papéis, apropriações do saber, comportamentos e resistências. Em Livros de devoção, atos de censura: ensaios de história do livro e da leitura na América Portuguesa (1750-1821). São Paulo: Hucitec, 2004, Algranti elucida detalhes relacionados às práticas de leitura na América portuguesa, aos atos de censura e à circulação dos livros nos séculos XVIII e XIX. Chamamos a atenção, igualmente, para as pesquisas de SILVA, Maria Beatriz Nizza da. As obras Sistema de casamento no Brasil Colonial. São Paulo: Edusp, 1984, e Vida privada e quotidiano no Brasil na época de D. Maria e D. João VI. 2. ed. Lisboa: Estampa, 1996, situam-se no conjunto de trabalhos que, no Brasil, privilegiam as estruturas domiciliares e apresentam, em seu em bojo, a preocupação com as constituições familiares e o universo feminino. Os trabalhos produzidos e/ou coordenados por DEL PRIORE, Mary Lucy M. constituem referência teórica e metodológica acerca da história das mulheres no Brasil. Sua tese de doutorado, Ao sul do corpo: condição feminina, maternidade e mentalidades no Brasil Colônia (1990), e publicações posteriores, de forma inovadora, elucidaram aspectos fundamentais das vivências e sociabilidades femininas. A obra História das mulheres no Brasil. 3. ed. São Paulo: Contexto, 2000, por ela organizada, tece reflexões sobre o feminino na história do Brasil ao longo de diferentes períodos e analisa o conjunto de investigações produzidas relacionadas ao tema da feminilidade. Da mesma maneira, as pesquisas de Luciano Figueiredo são referências indispensáveis para a compreensão do lugar ocupado pelas mulheres na sociedade mineira colonial. FIGUEIREDO, Luciano Raposo de Almeida. $O$ avesso da memória: cotidiano e trabalho da mulher em Minas Gerais no século XVIII. Rio de Janeiro: José Olympio, 1993; FIGUEIREDO, Luciano Raposo de Almeida. Barrocas famílias: vida familiar em Minas Gerais no século XVIII. São Paulo: Hucitec, 1999. 


\section{A escrita no Antigo Regime: reflexões}

Ao discorrer sobre os diferentes significados atribuídos à arte da escrita no Antigo Regime, Márcia Almada esclarece-nos que no contexto em pauta, relativamente à materialidade do ato, a escrita foi assim definida pelo padre Raphael Bluteau, inspirado em "uma passagem de Francisco Rodrigues Lobo, em Corte na aldeia":

O escrever não é outra coisa, mais que suprir com um instrumento por meio da arte e das mãos, o que com a voz se não pode exprimir e alcançar com os ouvidos, ou por distância de lugar, como quem escreve aos ausentes, ou por discurso de tempo, como quem escreve aos vindouros. ${ }^{16}$

Nesse sentido, Almada esclarece que a definição de escrita até o século XVIII funde-se com a ideia de caligrafia. Para a autora, este último termo somente apareceu nos dicionários a partir da terceira década do Dezenove, sendo entendido, em viés artístico, como a arte de grafar com rigor e exatidão, transcrever, com precisão e estética, o já registrado. Ao passo que callígrafo seria o indivíduo cuja letra é bem feita e perfeitamente compreensível. Se, por um lado, até o século XVIII, escrita é sinonimizada à caligrafia, reduzindo a possibilidade de escrever ao detentor da habilidade de desenhar as letras com perfeição, por outro, torna-se plausível pensar que a transferência do pensamento para o papel não se daria, necessariamente, pelas mãos de quem escrevia. Para Almada, a referida sinonímia traduz a compreensão da escrita enquanto "ação que possibilita a concretização visual e material do texto sobre um dado suporte e, tal como o próprio texto, expressa atitudes, pensamentos e simbologias específicas de cada época e sociedade"17.

Logo, podemos indagar: se a escrita assume a propriedade de instrumento revelador da mentalidade de um tempo, e se no período con-

16 No texto desta obra se evidencia também a diferenciação entre os significados de escrita e caligrafia e as definições elaboradas por especialistas no Antigo Regime. ALMADA, Márcia. Das artes da pena e do pincel: caligrafia e pintura em manuscritos no século XVIII. Belo Horizonte: Fino Traço, 2012. p. 33 .

17 ALMADA, Márcia. Das artes da pena e do pincel: caligrafia e pintura em manuscritos no século XVIII. Belo Horizonte: Fino Traço, 2012. p. 33. 
siderado essa habilidade era atributo de poucos, como se comunicaram aqueles que não a detinham, vencendo a distância espacial e temporal? De que modo fizeram valer seus direitos e se posicionaram diante das instâncias representativas do poder? Por quais meios registraram e formalizaram suas demandas, interesses e disposições?

Enquanto mecanismo descortinador de pensamentos e simbologias especificas de cada época e sociedade, os textos possuem autorias diferenciadas, pois diferentes são os pensamentos e intenções que veiculam. Dessa forma, são/foram forjados por distintos caminhos, porquanto os excluídos da escrita também dela se valeram ao longo de suas vidas.

A esse respeito, isto é, da utilização e apropriação dos códigos e/ ou da lógica escrita pelos iletrados ${ }^{18}$, Bouza Álvarez registra:

As notícias que testemunham o contato da população analfabeta com a escrita que não podiam entender por si próprios são tão abundantes que permitem romper as barreiras estabelecidas pela historiografia entre as culturas letrada e iletrada. Seja mediante a leitura em voz alta ou o sermão, seja por meio da delegação da escrita a terceiros, os analfabetos tomaram contato com os textos escritos e conviveram cotidianamente com eles, chegando inclusive a ser seus proprietários. ${ }^{19}$

Pelo exposto, e pensando na realidade da América portuguesa, é correto afirmar que, em suas condutas rotineiras, os sujeitos enredaram formas de ler e de escrever características da utilização da linguagem escrita também pela população não letrada. Tais práticas retiram o véu existente sobre o uso dos códigos culturais e fazem-nos perceber que esses são vivenciados e compartilhados para além das fronteiras das distinções sociais. No desenrolar

18 O sentido dos termos não letrado e/ou iletrado, neste trabalho, não é o de expressões contrárias à acepção de letrado no século XVIII. Aqui, nomeamos iletrado a quem não escrevia/grafava nenhuma palavra ou àquele que registrava apenas o próprio nome e/ou sinais equivalentes. Isso não significa equipará-los a analfabetos ou a não detentores de algum grau de letramento, no sentido conferido ao último conceito na atualidade. Pelo contrário, acreditamos que por viverem em uma sociedade perpassada pela escrita, esses sujeitos, provavelmente, estabeleceram relações com a mesma, fator propiciador do desenvolvimento de níveis de letramento. Há de se considerar, ainda, o fato de o aprendizado da leitura e da escrita acontecer em momentos dissociados (aprendia-se a ler antes de escrever). Por consequência, muitos desprovidos da técnica de escrever poderiam ser leitores.

19 BOUZA ÁLVAREZ, 2001, p. 68 apud ALMADA, 2012, p. 35. 
das vivências e experiências e na narrativa das mesmas, diferentes segmentos da população, entre eles os não letrados, "escreveram" suas trajetórias partilhando da "cultura letrada", código cultural destinado a outros grupos sociais.

É sabido que o domínio da cultura letrada possibilitava distinção e ascensão social e que a posse e o uso dos impressos, bem como a propriedade das maiores bibliotecas particulares, faziam parte do mundo dos proprietários e/ou daqueles que exerciam atividades que demandavam certa formação intelectual. Assevera-se, grosso modo, que a escrita estaria, majoritariamente, nas mãos masculinas, brancas e abastadas, o que está dito e redito pela historiografia. ${ }^{20}$ Não discordamos dessa análise, porém advogamos a necessidade de se levar em conta outras perspectivas de estudo respeitantes à escrita.

Buscamos rastrear, assim, quem eram os emissores das mensagens escritas. Essa tentativa parte da convicção de que não necessariamente, ou coincidentemente, eram eles os donos das mãos redatoras dos textos. Se, em muitos casos, quem lia era também quem ouvia e interpretava, por que não pensar que, em diferentes ocasiões, quem escrevia era aquele que ditava o texto, ainda que seu conteúdo fosse elaborado de forma compartilhada?

Por certo, importa bem menos conhecer se as mulheres escreveram por suas próprias mãos do que como escreveram e com quais intenções. Interessa-nos retirar desses relatos pistas sobre como tornaram inteligíveis sentimentos e esperanças e tentar compreender a forma pela qual a narrativa era construída e articulada para o atendimento de seus anseios. Entendemos que tanto nos espaços religiosos quanto na vivência domiciliar ou ao ditar, as mulheres absorveram elementos da cultura escrita ao travarem contato com discursos sociais organizados de acordo com essa lógica. Isso se deu principalmente por meio da leitura de oitiva, realizada tanto no interior de instituições, as quais tiveram importante papel na instrução feminina, quanto fora dos muros institucionais.

A menção à existência de cartas, cadernos de lembranças, "papéis" e documentos escritos não é incomum nas narrativas testamentais. Tais registros denotam a convivência com a palavra escrita que não se vinculava

20 Especialmente para o caso de Minas Gerais, no século XVIII, ver as obras já referidas neste artigo: VILLALTA (1999); ALVARENGA (2003) e também ANTUNES, Álvaro de Araújo. Os ânimos e a posse de livros em Minas Gerais (1750-1808). In: ALGRANTI, Leila Mezan; MEGIANI, Ana Paula Torres (Org.). O Império por escrito: formas de transmissão da cultura letrada no mundo ibérico. São Paulo: Alameda, 2009. p. 255-263. 
necessariamente às habilidades de ler e escrever. Notamos, pela análise das fontes, que "guardados" e segredos escritos, anotações e apontamentos penetravam o espaço doméstico, indiciando certa familiaridade com o registro grafado, apesar de tímida ou reservada. Por conseguinte, diríamos que, independentemente dessa convivência, a escrita desponta e se materializa na vida dos sujeitos como fator gerador de participação social. Participação processada, veementemente, via redação mediada, a qual tem sua gênese na "enunciação oral"

A escrita permitiria, ainda, a entrada em cena de diferentes agentes nas relações de poder. Eclesiásticos, tipógrafos, aristocratas, livreiros, censores e os próprios autores. São atores do processo de elaboração e divulgação dos materiais escritos. Desse modo, torna-se importante novo entendimento das relações de poder (incluindo-se aí os sujeitos comuns), sendo que o enfoque dos textos no Antigo Regime deve acontecer de maneira mais horizontalizada. Ou seja, não devemos hierarquizar a importância dos textos. Consoante Rodrigo Bentes Monteiro:

Em uma sociedade do Antigo Regime, como distinguir aparência de essência, representação e natureza do poder, o individual do estamental, o privado do público? Em todos os casos os extremos interpretativos são perigosos. Mas fica claro que os tratados jurídicos e os decretos administrativos, por exemplo, não podem ser hierarquizados como textos mais relevantes que a elaboração e a descrição de uma festa. Ambas as fontes são significativas para o entendimento do poder na Época Moderna. ${ }^{22}$

A partir dessa constatação é que consideramos o caráter social e histórico da linguagem, particularmente em sua dimensão escrita, e buscamos

21 A esse respeito ver: ONG, Walter J. Oralidade e cultura escrita: a tecnologização da palavra. Trad. Enid Abreu Dobránszki. Campinas: Papirus, 1998. De acordo com esse autor, devemos pensar que a enunciação oral parte de um agente específico e é sempre dirigida a outro indivíduo, também contextualizado, fator que faz com que as palavras adquiram nova dimensão ao estarem impregnadas das marcas do vivido. Ao "dizerem" suas crenças e necessidades, as mulheres, pelas vias burocráticas, adequaram aspectos da vida cotidiana à lógica escrita. A despeito da transformação da consciência humana gerada pela escrita, cabe salientar que esse processo encontra-se, sempre, relacionado à oralidade. A ideia de que a escrita transforma a consciência humana perpassa as obras de diferentes autores. Outro ponto comum nas abordagens diz respeito ao fenômeno da descontextualização. Ver: OLSON, David R.; TORRANCE, Nancy. Cultura escrita e oralidade. Trad. Valter Lellis Siqueira. São Paulo: Ática, 1995.

22 MONTEIRO apud ALGRANTI; MEGIANI, 2009, p. 201-228. p. 204. 
identificar usos que estão impregnados pelos conflitos e tensões. Como nos esclarecem Ana Maria de Oliveira Galvão e Eliana Marta Teixeira Lopes, "as relações e mediações ocorridas entre indivíduos e grupos sociais e o mundo da cultura escrita são muito mais complexas", pois que esboçadas em quadros diferenciados. Grupos inscritos em tradições marcadas pela oralidade, muitas vezes, desenvolvem táticas diferentes daquelas utilizadas por grupos naturalmente vinculados ao mundo letrado ${ }^{23}$.

Thais Nívia de Lima e Fonseca auxilia-nos a entender os critérios de definição do que poderia constituir-se como uma relação dos sujeitos com a escrita, especialmente na Colônia. Partindo de análise desenvolvida por Júnia Ferreira Furtado, aprofunda a reflexão e amplia a compreensão sobre o tema:

Júnia Ferreira Furtado chamou a atenção para o fato de que o domínio da linguagem escrita não servia, apenas, como instrumento de poder numa sociedade preconceituosa em relação aos trabalhos manuais. Entre os comerciantes, o conhecimento da escrita e da leitura era ainda mais importante para o exercício de suas atividades, considerando-se a possibilidade de um nível elevado de letramento nesse grupo. O indicativo utilizado é um pouco precário - a capacidade de assinar o nome - mas pode ser combinado a outros, como a posse de livros, frequente entre os comerciantes, e a preocupação recorrente com a educação dos filhos, na aprendizagem da leitura e da escrita, principalmente. Tudo isso permite fazer aquela afirmação de maneira mais segura. $^{24}$

Com base nesses esclarecimentos, podemos pensar as ações femininas associadas à escrita a partir de outro prisma, buscando historicizar as práticas daí decorrentes. Ressaltamos, também, o fato de que, no período em questão, "a escritura comercial encerrava um código linguístico próprio"25.

23 GALVÃO, Ana Maria de Oliveira; LOPES, Eliane Marta Teixeira. História da educação. Rio de Janeiro: DP\&A, 2001. p. 370.

24 FONSECA, Thais Nívia de Lima e. Portugueses em Minas Gerais no século XVIII: cultura escrita e práticas educativas. Anais do II Encontro Internacional de História Colonial. Revista de Humanidades, Caicó-RN, v. 9, n. 24, p. 1-8, set.-out. 2008. p. 7.

25 FURTADO, Júnia Ferreira. Uma correspondência de negócios nas Minas setecentistas: possibilidades de leituras. In: ABREU, Márcia et al. (Org.). Cultura letrada no Brasil: objetos e práticas. Campinas: Mercado de Letras/Associação de Leitura do Brasil, 2005, p.119-139. p. 269-397. p. 137. 
No contexto do Antigo Regime, a utilização da escrita, via ditado, conferiu realce aos posicionamentos sociais. Forjou identidades, definiu destinos, delineou representações sociais, manifestou-se, enfim, como poder que dependeu, fundamentalmente, da capacidade de verbalização, isto é, da enunciação dos indivíduos.

A esse propósito, evocamos as considerações de Ivan Illich, quando afirma que é preciso pensar que as transformações mentais e cognitivas, a compreensão e o saber se expressam e acontecem mesmo na ausência das habilidades de leitura e escrita. Por conseguinte, a ideia de que tais transformações ocorreriam somente a partir do domínio da escrita é falsa. Nas suas palavras: "Desde a Idade Média, as certezas que caracterizavam a mentalidade dos que aprendiam a ler e a escrever difundiram-se, de maneira surpreendente, por meios que extrapolam o ensino da capacidade de ler e escrever". 26

Questões essenciais emergem da reflexão sobre como letrados e não letrados comungam da mentalidade própria de uma sociedade legitimada pelo registro alfabético. A mentalidade da sociedade gestada e legalizada pela escrita é, na verdade, uma singularidade histórica. Illich sugere que os historiadores da educação deveriam se preocupar com os fenômenos ocorridos dentro do espaço da cultura alfabética, obrigando-se a explorar esse ambiente. As pesquisas precisam, assim, reconhecer a heteronímia do espaço da escrita com relação a três outras áreas: a oralidade, as realidades moldadas pelas notações não alfabéticas e a mentalidade cibernética. Para o autor, muitos "analfabetos" tomam parte da ilha do alfabeto. A mente desses pode também pertencer a um contexto caracterizado pela escrita. ${ }^{27}$

26 O autor comunga das análises de Ong (1998), defensor da proposição de que a alfabetização equivale a uma tecnologização da palavra, e ressalta que as pesquisas relativas à mentalidade da cultura escrita devem ser aplicadas à educação. Para ele, os estudos da teoria da comunicação afirmariam como o texto pode ser elemento revelador, no contexto, da mentalidade da cultura escrita. Compartilha, dessa forma, a ideia defendida por Paul Ricoeur (1989) de que o texto pode explicitar características da própria historicidade do sujeito, deixando à mostra dimensões da experiência humana. Ver: ILLICH, Ivan. Um apelo à pesquisa em cultura escrita leiga. In: OLSON, David R.; TORRANCE, Nancy. Cultura escrita e oralidade. Trad. Valter Lellis Siqueira. São Paulo: Ática, 1995. p. 35-54. p. 38. Sobre as relações entre texto e historicidade do sujeito, cf.: RICOEUR, Paul. Do texto à acção: ensaios de hermenêutica II. Trad. Alcino Cartaxo e Maria José Sarabando. [Porto]: Rés, 1989.

27 Interessante abordagem de Illich refere-se ao lugar ocupado pelo computador dentro do espaço da cultura escrita. Segundo o autor, o computador não ameaçaria a cultura escrita, uma vez que se trata de rede de termos e ideias que conecta um novo conjunto de conceitos cuja representação comum é o computador. Para ele, "a mentalidade cibernética engole um novo tipo de leigo", fenômeno que, de maneira geral, a educação ainda não acompanha. Cf. ILLICH (1995, p. 52). 
De maneira semelhante, concernente à aproximação dos iletrados aos contextos marcados pela escrita, Roger Chartier, ao analisar as práticas urbanas de leitura nos séculos XVII e XVIII na França, afirma que a leitura não deve ser tomada como invariante histórica, uma vez que existem diferentes usos do que foi escrito e modalidades de ler que variam de acordo com as épocas e os lugares. Reflexões que, se transportadas para o campo das práticas ou modalidades de escrita (e não apenas das leituras), reforçam a importância de se tentar identificar as redes de pertencimento dos sujeitos.

Datada que é, a escrita do período em foco somente e obviamente poderá ser trabalhada em sua historicidade, marcada por fatores externos à sua constituição, os quais caracterizavam o contexto em que foi produzida. Neste ponto, frisamos a relevância do ditado, do aspecto oralizante enquanto condicionante social do período. Trata-se, nesse sentido, de um movimento paradoxal, pois, ao mesmo tempo que trabalhamos com o registro escrito, fixado no papel, ressaltamos o lugar de destaque assumido pela fala dos iletrados em nossa investigação. Fala e escrita são fenômenos entrelaçados e não dicotomizados.

Percebemos, portanto, a importância da cultura do contexto em questão, isto é, das práticas sociais aí processadas. Na realidade, concordamos com a ideia da existência de diferentes culturas escritas ou uma cultura do escrito característica de cada época. Explicitemos: entendemos que no caso da escrita testamentária, presente na sociedade colonial, havia um modus operandi, isto é, certa forma de se escrever própria a determinado gênero textual ${ }^{28}$. $\mathrm{O}$ ato de testar pode ser tomado, desse modo, como uma situação comunicacional, da qual participavam letrados e iletrados. Mesmo sem saber escrever, os testadores seriam, nesta perspectiva, autores orais, porquanto partícipes e conhecedores do contexto. Por isso, acreditamos que os textos produzidos carregam marcas de sua autoria ${ }^{29}$, as quais são verificáveis a partir de expressões comuns àquele período.

No caso da sociedade colonial, para a análise da redação dos testamentos, um dos caminhos escolhidos para reconhecimento das marcas de

28 Sobre tal matéria ver ARIÈS, Philippe. O homem diante da morte. 2. ed. Trad. Luiza Ribeiro. Rio de Janeiro: Francisco Alves, 1989. v. 1.

29 A respeito do aparato teórico-metodológico utilizado para identificação das marcas de autoria nos textos testamentais, reporte-se à tese de doutorado, da qual este artigo se origina, intitulada Por mãos alheias: usos sociais da escrita na Minas Gerais colonial. Banco de teses da biblioteca da Faculdade de Educação da UFMG. 
autoria dos textos foi a menção às crias da casa. A partir da identificação dessa expressão, processamos o deslindamento e a interpretação dos conteúdos textuais, como veremos a seguir.

\section{Pelo muito amor que lhe tenho: crias da casa na redação dos testamentos}

Na casa de Maria do Nascimento Vieira, situada na Freguesia do Sabará, a escrava Rosa trabalhava. A morada ficava no sítio do córrego do Tamanduá, "com suas casas de vivenda de telhas", possuía engenho de cana com alambique de destilar aguardente e uma caldeira de duas talas. Lá, Rosa torrava farinha de mandioca e via crescer seu filho, Francisco, cria da casa, em meio ao pasto com os quatro bois e o cavalo de seus proprietários. Rosa, que havia começado a pagar pela alforria do filho, esperava vê-lo livre do cativeiro. Sua senhora e proprietária, Maria do Nascimento, sempre moradora na dita freguesia, era casada com Antônio de Sousa Pereira e não tivera filhos. Para honrar a dívida com a mãe de Francisco, determinou que, após seu falecimento, o referido escravo fosse coartado, desde que servisse ao seu marido, fazendo por merecer a liberdade, a juízo de Antônio de Sousa. Quando da feitura do testamento, em 30 de agosto de 1781, Maria do Nascimento afirmou:

\footnotetext{
Declaro que o crioulo Francisco, depois que eu falecer, ficando por herdeiro meu marido, há de se abater [o] que lhe devo por um crédito e, se ele merecer, meu herdeiro o coartará pelo que ele valer, ficando em conta o dito crédito que eu devo à mãe do dito [...] por falecimento do meu herdeiro que antes disso lhe há de servir como seu escravo que sempre o foi. (MO/CBG/ CPO/LT 51(70), fls. 110-114v).
}

Ao ditar o testamento, a senhora de Francisco utiliza-se da escrita para honrar a dívida, decisão corriqueira durante a elaboração desse documento. No entanto, mais do que pagá-la, a testadora demonstra em seu 
discurso a capacidade de condicionar a alforria ao merecimento do escravo. A presença desse tipo de argumentação e exigência nos textos testamentais também não era incomum. Na sociedade mineira setecentista praticavam-se coartações, alforrias condicionais, bem como a concessão de liberdade aos filhos de cativas nascidos na casa do proprietário, denominados, por isso, crias. Tais aspectos determinam o conteúdo da redação, as funções e as formas de utilização da escrita: certo estilo ao elaborar o texto.

Disposição, condicionamento/justificativa e "resultados" (ou hipóteses) sobre a determinação feita compõem a triangulação que encaminha e tonaliza as funções da narrativa escrita. A redação do texto de Maria do Nascimento demonstra o conhecimento de prática relacionada ao universo escravista e a utilização da escrita para explicar as motivações e as possíveis consequências de seus atos. Atitudes como descrever e precisar a forma como se dariam as liberdades das crias, por exemplo, trazem à tona práticas mais íntimas guardadas em relacionamentos microscópicos, domésticos, muitas vezes ofuscadas pelas explicações sistêmicas da história.

$\mathrm{Na}$ escrita dessas experiências, princípios morais e religiosos, conformadores de um imaginário, mesclam-se às vivências diárias e específicas que, se também desse imaginário fazem parte, apresentam características particulares. Esses registros recheiam as redações dos testamentos e encontram-se apoiados nas ocorrências familiares diárias, no desenrolar das relações sociais, nas transações comerciais, por fim, no contexto extraverbal. Do mesmo modo, pautam-se nos sentimentos estabelecidos entre os sujeitos. As características escriturais denotam determinações que descortinam o conhecimento não apenas das lógicas de funcionamento da sociedade, mas das maneiras como esse funcionamento deveria ser relatado, documentado e "guardado", num espaço interno de comunicação.

Ao "escrever": o "herdeiro meu marido, há de se abater", do escravo Francisco, "o que lhe devo por um crédito" e somente "se ele merecer meu herdeiro o coartará", Maria do Nascimento narra a aquisição da dívida com a escrava Rosa e, na sequência, dispõe sobre como lidar com a situação de Francisco. Assim, pela oralidade, "escreve" os pontos de referência de sua relação com os escravos, tanto no que tange a episódios passados quanto a possíveis acontecimentos futuros. Nessa perspectiva, fala sobre o crédito que Rosa possuía com ela, da necessidade e do desejo de Francisco servir ao seu herdeiro de forma adequada para, posteriormente, ser alforriado. Trata- 
-se da narração de acontecimentos pessoais que se encontravam ancorados em marcas sociais, sendo que ambos, porque conectados e simultâneos, estruturam a memória coletiva.

O texto apresenta-se, portanto, relacionado ao social ao mesmo tempo que remete a individualizações. A proprietária de Rosa, que possuía outros escravos, "Francisco crioulo, Cristóvão angola, Miguel, Manuel, Francisco congo e Josefa", acreditou ser indispensável registrar em seu testamento as disposições referentes à coartação desta última, também deixada ao marido e herdeiro. A esse respeito afirmou: "Declaro que a negra Josefa também passo a meu marido, que por sua morte a coarte dando tempo para procurar o seu valor". No entanto, no caso do escravo Francisco, utilizou-se da escrita para alforriá-lo de forma condicionada, detalhando suas disposições, o que não foi feito ao se referir a Josefa. Revelou, assim, a construção de uma memória sobre o acontecido, a aquisição da dívida com Rosa, e de uma identidade social no que respeitava às decisões da vida familiar: legado dos bens e coartações. Independentemente de saber escrever, relatou determinações diferenciadas, compondo um documento nuançado, autônomo e único. Lidando com desenvoltura no registro de suas decisões, utilizou-se socialmente da escrita na produção de seu texto.

A fluência em lidar e ditar temáticas do cotidiano, referindo-se à cria, pode ser identificada, de maneira semelhante, no testamento de dona Teresa Andrada Soto Maior, elaborado em 19 de outubro de 1793. Além de ter dívidas a honrar, dona Teresa "assinou" o documento em cruz e declarou não saber ler nem escrever. Entretanto, demonstrou desenvoltura ao ditar suas disposições e ao utilizar a redação do testamento de maneira dinâmica, referindo-se aos bens que possuía e aos sentimentos que dizia cultivar por determinada ex-escrava, Faustina, cria em sua casa. Com essa intenção, declarou:

Possuo escravos e umas lavras na vizinhança do Arraial de São Gonçalo do Caeté aonde tem minha situação, a qual consta de títulos que tenho: as dou pelo amor de Deus à crioula Faustina, que foi minha escrava, cria e é hoje forra, e aos mais escravos que coartei para que morem na dita situação, trabalhem nas ditas lavras, unidos em boa paz como suas que ficam. (MO/ CBG/CPO/LT 37(55), fl. 167, grifo nosso). 
A descrição de seu sentimento pela ex-escrava apresenta elementos da religiosidade, vozes sociais que informam sua enunciação, como a afirmativa "pelo amor de Deus", denotando a devoção religiosa e a virtude da compaixão pela "crioula Faustina". Além dessa característica, recorrente nos testamentos, a narrativa da testadora demonstra organicidade e lógica. Inicialmente, dona Teresa descreve a situação desta ex-escrava, justificando sua "doação", pois, em ordem de importância do lugar ocupado pelos ex-escravos, relata o fato de Faustina ter sido não apenas escrava, mas cria, sendo naquela altura forra. Somente depois, talvez diminuindo a importância dos outros que foram escravos, mas não necessariamente crias em sua casa, dispõe acerca do que também virá a lhes pertencer, ou seja, as "lavras na vizinhança do Arraial de São Gonçalo aonde tem minha situação".

A lembrança de dona Teresa da ex-escrava Faustina como cria não se deu de maneira "completa", de forma a remontar o passado tal qual ele era. Memórias não são espelhos da realidade, mas reconstruções elaboradas a partir dela. As recordações são sempre fragmentadas, compõem-se de estilhaços do vivido, das seleções e escolhas feitas por quem narra, pelos sujeitos autores das lembranças. Esses "sujeitos-autores" lançam o olhar para o passado, mas alicerçados em novas bases, em experiências presentes, particulares. Daí decorre o entendimento de que as lembranças apresentam caráter subjetivo, mesmo compartilhadas coletivamente e reconstruídas a partir, inclusive, de elementos pertencentes a uma memória coletiva.

Diferente foi, ademais, a narrativa de Maria de Sousa Nascimento sobre suas crias. Essa testadora nascera na Vila de Sabará, era viúva de Domingos Rodrigues e mãe de dez filhos. O testamento, assinado em cruz, fora elaborado na fazenda Boa Vista, em 6 de outubro de 1776, quando Maria ordenou que seu corpo morto fosse envolto no hábito da Arquiconfraria de São Francisco, “[...] onde tinha vontade de entrar por irmã e professar, pagando esmola que for justa e pretendo fazer $[\ldots]$ " $(\mathrm{MO} / \mathrm{CBG} / \mathrm{CPO} / \mathrm{LT}$ 39(58), fls. 91-95).

Ao ditar as disposições, afirmou: "[...] quando por algum incidente eu não consiga entrar na dita irmandade então serei sepultada na minha matriz em hábito de São Francisco, bem entendido que é na Igreja de Santo Antônio da Roça Grande". Notemos que a testadora utiliza-se da redação do testamento para explicar minuciosamente onde desejava ser enterrada. Para que fossem evitados quaisquer enganos, argumenta no sentido de deixar 
"bem entendido" o lugar correto para o sepultamento, denotando a consciência do almejado, isto é, entrar na Irmandade de São Francisco poderia não se concretizar. Precisou, então, empregar recursos verbais para explicar como deveria ser realizado o sepultamento. Certamente o redator escreveu de maneira a reforçar essa determinação, mas, muito provavelmente, o fez pelo fato de a narradora do texto ter enfatizado tal aspecto. No desenrolar do ditado afirmou possuir:

[...] [Um] sítio e seus pertences, de alguns [matos], ainda que muito poucos, casa de vivenda coberta de telhas, senzala e paiol coberto de capim e engenho de mandioca já danificado e uma capoeira junto ao Rio das Velhas [...] mais escravos seguintes: Gonçalo, crioulo; Francisco, crioulo; Jorge, crioulo; Domingos Benguela; Antônio Mina; Joaquim Benguela; João da mesma nação; Rita crioula; Sebastiana crioula; Caetana crioula; Vitoriana crioula; Francisca parda; Joaquina parda, filha da dita; Francisco e João pardos, filhos da mesma; Rosa aleijada, filha da dita crioula Sebastiana. (MO/CBG/CPO/LT 39(58), fls. 91-95).

A testadora consegue precisar os nomes de todos seus escravos, de onde provinham e de quem eram filhos. Constrói, desse modo, narrativa detalhada, mencionando, por exemplo, o fato de a filha da crioula Sebastiana ser aleijada. Demonstra ter conhecimento do plantel possuído, fator devido, talvez, à administração de sua propriedade, visto ser viúva. A despeito de ter dez filhos que poderiam se dedicar aos negócios familiares, a testadora narra pormenores acerca das posses e finanças da família e como deveriam ser encaminhadas. Mesmo sem saber escrever, visto marcar o testamento com uma cruz, Maria do Nascimento deixa transparecer em sua narrativa o domínio da administração da casa, construindo texto preciso e coeso. Ao nomear cada escravo e não apenas quantificá-los, reforça a propriedade de seus bens e utiliza-se da escrita de modo a reafirmar o senhorio sobre os mesmos. Dando sequência às suas disposições, afirma:

[...] a meu filho Guilherme dei por conta de sua legítima paterna uma crioula por nome Teresa e a meu filho Joaquim um pardo por nome Manuel, sendo este ainda de menor idade, também por conta de sua legítima paterna, e a minha filha, senhorinha 
Maria, se juntou oito mil e quatrocentos; e a meu filho Sebastião quarenta e duas oitavas. Declaro que uma mulata, por nome Joana, deixou o falecido meu marido tomando [?] na sua terça para me servir e as suas filhas, Maria e Ana, até estas se casarem e que casadas ele lhe passe assim sua carta de liberdade, e por isso as ditas minhas filhas, visto se não terem ainda até o presente casado, farão a dita mulata Joana o benefício que muito quiserem e lhes parecer [...]. (MO/CBG/CPO/LT 39(58), fls. 91-95).

Com suas determinações, define o destino dos cativos, bem como deixa entrever na narrativa as negociações e decisões realizadas, tomando-se os escravos efetivamente como mercadorias a serem legadas. Explica com clareza o que havia sido disposto por seu falecido marido, regressando aos legados que ele lhe conferira. $\mathrm{O}$ texto produzido cumpre, nesse trecho, a finalidade de recuperar acontecimentos e resoluções. Nesse sentido, esclarece como tinha procedido em relação às legítimas dos filhos, expondo, assim, um pouco da história familiar.

Em seu ditado, atribui às filhas autonomia para que procedam da maneira que julgarem melhor com relação ao destino da cativa Joana. Este último aspecto é denotativo do poder que a escrita do testamento confere a Maria do Nascimento, pois essa disposição acaba por desfazer determinação de seu falecido marido. Declara que,

[...] por reconhecer que uma parda minha escrava por nome Maria Vitória, filha da dita parda Joana, é minha sobrinha, por ser filha de meu irmão João da Costa, é minha vontade que fique liberta, para o que a tome na minha terça, com a obrigação do dito seu pai mandar dizer oitenta missas de esmolas de meia oitava por minha alma ou ainda a dita parda e com apresentação da certidão [...] peço e rogo muito de [fazer] a meus filhos e herdeiros que se haver quem queira libertar e a alguns dos pardos ou pardos que forem crias de minha casa, dando a seu justo valor, que lhes convenham em lhes fazer esta equidade [...] pelo amor [?] que lhes tenho, os desejos ver a todos bem amparados. (MO/CBG/CPO/LT 39(58), fls. 91-95).

Aqui, torna-se importante destacar que o reconhecimento do parentesco com a parda Maria Vitória concede certa singularidade ao texto. A 
viúva de Domingos Rodrigues não reafirma disposições do marido, mesmo que em parte modificadas, mas revela ter tomado as decisões a partir de determinado conhecimento. É possível que o nascimento da cativa ou a revelação de tal parentesco tenha se dado apenas após a morte do marido da testadora. De qualquer modo, a percepção da realidade acabou por orientar e instituir a redação de seu texto. Redação, aliás, que, para ser construída, extrapolou o mero relato de informações adquiridas pela testadora e demandou a capacidade de avaliar as atitudes a serem tomadas quando da posse dessa informação, para mais tarde firmá-las no papel.

Em relação às crias da casa, a testadora pede e roga aos herdeiros que, desejando libertá-las, assim o façam, dado o amor que lhes declarava sentir. Numa primeira leitura, parece que, novamente, por meio da escrita do testamento, Maria de Sousa atribui autonomia aos herdeiros para agirem como melhor julgassem. No entanto, na sequência da frase, alerta sobre o amor que dizia ter pelas crias, como se buscasse com seu argumento convencer do quanto apreciaria caso "alguém" proporcionasse a elas a liberdade. Benevolência que a testadora gostaria apenas de demonstrar com sua narrativa? Talvez. Se sua intenção era conferir a liberdade às crias, por que não o fez? Contudo, se, por um lado, Maria não as liberta, por outro, da maneira como constrói a narrativa, deixou as portas abertas para que isso ocorresse. Ao mencionar a libertação das crias por quantia justa, coloca a manumissão enquanto uma equidade, podendo ser realizada por outros, a partir da autorização dos herdeiros. Atribuiu, assim, valoração à liberdade, considerando-a como respeito à igualdade de direitos que as crias teriam em relação aos outros cativos. Por fim, dispôs sobre as dívidas e créditos, matéria costumeira dos testamentos:

Declaro que as dívidas que devo constam de créditos e obrigações; porém, sem embargo disso, se aparecer alguma pessoa bem conceituada que diga que lhe devo alguma coisa, sendo até a quantia de dez oitavas, meus testamenteiros, sem mais contenda e justiça e só com juramento da dita pessoa lhe satisfará; e ao meu testamenteiro deixo uma carta fechada para, debaixo de segredo natural, cumprir o determinado nela, sem ser obrigado a declarar o seu conteúdo e só assim o jurar que cumpriu o que lhe determinei. (MO/CBG/CPO/LT 39(58), fls. 91-95). 
Nesse trecho, o papel assumido pela oralidade, na sociedade colonial, aparece em destaque. Por um lado, com sua narrativa, Maria de Sousa, além de registrar as dívidas- as quais, muitas vezes, se firmavam apenas pelo empenho da palavra -, ressalta o valor que promessas de pessoa "bem conceituada" poderiam ter, independentemente da existência de anotações ou apontamentos. Por outro, no entanto, ao estipular o limite do valor de alguma dívida da qual porventura não se lembrasse, demonstra conhecimento do máximo que poderia ter contraído em empréstimo, utilizando-se da escrita de maneira a confirmar esse entendimento e a se preservar de futuras cobranças não correspondentes à realidade, no caso de eventuais alegações em contrário. Em igual medida, na elaboração do texto, revela-nos certo convívio com escriturações, ao afirmar que deixava ao testamenteiro "uma carta fixada" para cumprir, "debaixo de segredo natural", as disposições que contivesse.

As crias foram mencionadas por diferentes testadoras, mas também diferentes foram as maneiras como "escreveram" sobre elas. Francisca Gomes Pereira, natural de Santa Luzia, filha legítima de Francisco Gomes e de Antônia Pereira Baião, ao ditar seu testamento, em janeiro de 1803, dizendo não saber ler nem escrever, estabelece:

Declaro que sou senhora e possuidora de um moleque digo de um mulatinho por nome José e de um crioulo por nome Manuel, ambos filhos de duas escravas minhas, os quais ambos, por serem minhas crias, e pelo amor que lhes tenho, os deixo forros e libertos, e sendo necessário, meu testamenteiro lhes passará a cada um sua carta de liberdade. (MO/CBG/CPO/LT 58(77), fl. 7).

A escrita, uma vez mais, "serviu" para a legitimação das alforrias das crias e, ao mesmo tempo, para a demonstração dos afetos alegados por suas senhoras. Não estamos, é claro, afirmando que as alforrias, em suas modalidades, são frutos tão somente das concessões generosas e amorosas de seus senhores para com os escravos. Como nos mostra a historiografia, os cativos e forros foram protagonistas de sua história e construíram estratégias de resistência e de negociação relativas às vivências e atuações 
no cenário social..$^{30}$ Porém, a recorrência, nos textos analisados, de dizeres que pretendem revelar as supostas relações estabelecidas entre senhores e escravos, principalmente entre proprietárias e cativos ou ex-cativos, instiga-nos a problematizar acerca da necessidade e das formas como se efetuaram os registros dessas convivências.

Na fazenda de São Sebastião, localizada na freguesia de Nossa Senhora da Conceição do Rio das Pedras, por "atenção" ao fato de haver criado Antônia e em reconhecimento aos bons serviços por ela prestados, outra testadora, agora Vitória Gonçalves Geraldes, alforria sua escrava. Essa proprietária, que ditou seu testamento em 1795, rogou para que o assinassem. Mulher solteira, sem filhos, possuía especial devoção por São José e Santo Antônio, era filha natural do capitão Manuel Gonçalves Geraldes e de Teresa Gonçalves "preta mina". Leiamos trecho de seu testamento, feito em abril de 1795:

Declaro que na dita sociedade há uma crioula por nome Antônia e em atenção a havê-la criado e aos bons serviços que me tem feito, a deixo forra pela parte que me pertence e pela metade do que me pertence digo que pertence ao meu sócio quando ele não queira contribuir para este benefício, minha testamenteira lhe passará este valor a respeito a sua parte lhe passará carta de liberdade [...] (MO/CBG/CPO/LT 50(60), fls. 104-109).

Vitória explicita a situação de sua escrava Antônia. Segundo a testadora, a cativa encontrava-se na "dita sociedade", levando-nos a supor que a mesma vivesse em sua companhia. O fato de afirmar ter "criado" a escrava difere dos casos mencionados, os quais dizem respeito às crias. Criar implicava cuidados diretos, em um conjunto de atitudes voltadas a garantir a sobrevivência e o bem-estar, diferentemente das crias que eram filhas de

30 A este respeito ver, dentre outros: REIS, João José. Escravidão e invenção da liberdade: estudo sobre o negro no Brasil. São Paulo: Brasiliense, 1988; LARA, Sílvia Hunold. Campos da violência: escravos e senhores na Capitania do Rio de Janeiro, 1750-1808. Rio de Janeiro: Paz e Terra, 1988. Particularmente para a região estudada, sobre essas estratégias de resistência, ver PAIVA, Eduardo França. Escravos e libertos nas Minas Gerais do século XVIII: estratégias de resistência através dos testamentos. 2. ed. São Paulo: Annablume, 1995; GUIMARÃES, Carlos Magno. A negação da ordem escravista: quilombos em Minas Gerais no século XVIII. São Paulo: Ícone, 1988; RAMOS, Donald. O quilombo e o sistema escravista em Minas Gerais do século XVIII. In: REIS, João José; GOMES, Flávio dos Santos (Org.). Liberdade por um fio: história dos quilombos no Brasil. São Paulo: Companhia das Letras, 1996. p. 164-192. 
escravas e que nasciam nas casas dos proprietários, convivendo com os mesmos, mas cuja criação cabia à mãe. Todavia, numa ou noutra situação, a criança havia nascido ou pelo menos crescido na casa de seu proprietário.

Na narrativa de Vitória, há uma sequência lógica da apresentação dos acontecimentos. Em primeiro lugar, diz onde Antônia está, explica ser sua proprietária e a ter criado, determinando a alforria. Paga, inclusive, pela parte de seu "sócio", de forma a garantir a liberdade a Antônia. Para tanto, demonstrando conhecimento da realidade, orientou a testamenteira a passar o valor relativo ao preço da liberdade de Antônia a seu sócio, caso ele, de alguma maneira, se opusesse a alforriá-la. Ordenou ainda que, ao final do processo, a testamenteira passasse carta de liberdade à escrava.

Mesmo que o redator do texto, ou outra pessoa presente no ato, tenha dado, durante o ditado do testamento, organicidade ao conteúdo, é inegável a presença de elementos específicos, como o que a testamenteira deveria fazer para garantir a liberdade de Antônia e a explicação acerca da identidade dessa escrava, os quais possuem coerência, conferindo racionalidade à narrativa. Nesse sentido, a autora-oral trabalha com os fatos: a existência e a criação de Antônia; com hipóteses: com o que poderia dar errado no processo de alforria; e com resoluções: como garantir o cumprimento de sua determinação. Esse conjunto de elementos discursivos, quais sejam, fatos, hipóteses e resoluções, encadeia os acontecimentos, estabelecendo nexos entre eles. Mais do que mera disposição sobre o destino da escrava, neste caso a escrita assumiu a função de descritora das situações vividas, servindo para justificar as ações e para precaver possíveis desvios às determinações testamentárias.

Esse panorama ou caminho do escrito é característico da sociedade em estudo, ou seja, da sociedade colonial e/ou imperial escravista, pois nela os fatos mencionados ocorreram como descritos. Dito de outra maneira: no contexto referido as alforrias condicionais e as coartações dos filhos das escravas que viveram na casa de seus senhores fizeram parte da realidade histórica. Cabe frisar, portanto, que as características do contexto extraverbal são constituintes da forma, do estilo e do conteúdo. Em última instância, dos usos conferidos à escrita, mesmo por aqueles que não escreviam autonomamente.

Sem saber ler nem escrever e marcando seu testamento com uma cruz, em janeiro de 1794, na Freguesia de Nossa Senhora da Conceição do 
Rio das Pedras, Juliana Sanches da Silva registrou a respeito de suas crias Helena, Narcisa, Cecília, Perpétua, Bernardo, Maria e Vicência, filhos da escrava Maria, de "nação mina", já falecida. A testadora, sobre as referidas crias, determinou:

[...] pelos bons serviços que me fizeram e amor que lhes tenho, lhes tenho passado a carta de liberdade a cinco de junho de 1792 anos, com as cláusulas nelas declaradas e que, neste meu testamento, novamente as expresso a saber: Narcisa com a condição que daria para o meu enterro e sufrágios a quantia de quatorze oitavas, a Cecília com a obrigação de dar dezoito oitavas, cuja quantia já recebi e lhe entreguei a sua carta e na qual também libertei as suas duas filhas digo libertei as suas filhas Agostinha, Angélica e Luísa; Perpétua, com a condição de dar para o meu enterro e sufrágio a quantia de quatorze oitavas. Helena, com a condição de dar para o meu enterro e sufrágios a quantia de quatorze oitavas e na carta que lhe passei de sua liberdade lhes forrei os seus filhos: Antônio pardo, Luciano e Hilária crioulos; Bernardo com condição de dar para o meu enterro e sufrágios vinte oitavas de ouro, cujas cartas as conserva em seu poder o senhor alferes Eusébio Francisco Lopes e lhes serão entregues depois de cada um satisfazer a parte que lhes toca. (MO/CBG/ CPO/LT 47(66), fls. 137v-141).

O modo de Juliana elaborar e partilhar pensamentos e decisões sobre as crias é extremamente representativo da autonomia em escolher e compor aquilo que deveria ser firmado no papel. Na verdade, sua narrativa trata da socialização de hábitos, crenças, impressões, sentimentos e necessidades. Assume função descritivo-explicativa, referindo-se a relatos do passado e a determinações futuras. Os apontamentos deixam entrever aspectos da convivência com os cativos, expondo os acontecimentos cronologicamente, como, por exemplo, ao datar quando passara a carta de liberdade aos escravos.

Ademais, ainda que tenha sido estimulada e orientada a registrar tal momento, a testadora faz questão de reiterar as cláusulas contidas nas cartas. Costume da época, a reafirmação em testamento das liberdades concedidas aos escravos revela o uso da escrita de forma a ratificar decisões que já se encontravam legalizadas, prática, ao que parece, conhecida por nossas 
testadoras. Nesse sentido, vale lembrar que os textos postos no papel são retomáveis e verificáveis, passíveis de "esquadrinhamento retrospectivo"31, permitindo-se a eliminação das incoerências, as ratificações. Ressaltemos que, neste caso, o esquadrinhamento retrospectivo do que havia sido escrito deu origem a novo texto, o qual nasceu de uma enunciação oral. Revista e examinada, essa escrita compõe o quadro coerente explicitador de valores, crenças e hábitos.

Mais uma vez, a alforria condicional ganhou a cena e surgiu atrelada aos discursos sociais, mormente às crenças e aos hábitos religiosos. Dito de outra maneira, a escrita emerge relacionada ao espaço externo de comunicação. Minuciosamente, Juliana expôs as exigências para a efetivação das liberdades das crias, evidenciando uso circunstanciado da escrita. Outro aspecto relevante em seu testamento diz respeito à ordem assumida pelas disposições. Contrariamente ao "modelo" testamentário, a testadora inicia seu texto com as determinações acerca das coartações e apenas depois declara os bens que possui. Na sequência de seu testamento, explicita:

Declaro que os bens que possuo são uma morada de casas em que moro e alguns móveis de pouco valor cujas casas e móveis os deixo às minhas crioulas e crioulo acima mencionados, para nelas morarem, e os móveis a Narcisa e Cecília [que] os repartirão entre todos igualmente. Declaro que as crioulas Vicência e Maria já eram libertas porque assim as mandei batizar por forras. Declaro que para os sobreditos pagarem as referidas quantias lhes dará meu testamenteiro um ano, e tendo o recibo de cada um o que lhe toca, lhes entregará a sua carta e o mesmo tempo lhe concedo para mostrar em juízo satisfeitas as minhas disposições; e pago o meu funeral. (MO/CBG/CPO/LT 47(66), fls. $137 \mathrm{v}-141)$.

O que a escrita de Juliana nos parece revelar é certa hierarquia e lógica atribuídas às disposições em detrimento ao modelo rígido do texto. Isto é, de início Juliana evidenciou quem eram as crias e, logo em seguida, dispôs dos bens em favor das mesmas. Conferindo racionalidade ao discurso, inverteu o modelo ou padrão do documento, qual seja: encomendação do

31 GOODY, Jack. The domestication of the savage mind. Cambridge: Cambridge University Press, 1977. p. 49-50. 
corpo, disposição dos bens e depois as alforrias, para principiar a narrativa com a declaração das liberdades.

Tendo em vista que deixaria seus legados para Helena, Narcisa, Cecília, Perpétua, Bernardo, Maria e Vicência, é como se fizesse questão de apresentá-los no início do ditado, explicando as condições das manumissões, para mais tarde dizer sobre aquilo que herdariam. Ao "escrever", subvertendo a ordem do escrito, deixa-nos perceber, no texto, aspectos da narrativa que emana da oralidade, pois a redação não se encontra imobilizada pela ordem clássica do testamento. Ao contrário, mostra-se flexível e diferenciada. Mesmo existindo protocolos específicos que delineavam o conteúdo do documento, a testadora "redigiu" seus desejos e determinações, utilizando-se da escrita de maneira autônoma, liberta e pessoal.

\section{Algumas palavras a título de considerações finais}

Nas sociedades do Antigo Regime, o contato e o uso da escrita ocorreram, para os iletrados, por meio da escrita mediada. Esses sujeitos vislumbraram no ditado um mecanismo para vencer a incapacidade de redigir na solidão. A partir da enunciação oral, elaboraram textos sobre suas vidas, resgataram lembranças, construíram memórias, argumentaram, outorgaram e expressaram vontades. Essas constatações somente se fizeram possíveis com base em novo entendimento do conceito de práticas educativas. $\mathrm{Na}$ América portuguesa, de maneira geral, os processos de aprendizagem configuraram-se como fenômenos sociais ocorridos tanto nos espaços institucionais quanto fora de seus limites, como práticas que revelaram estratégias desenvolvidas pelos sujeitos para apreensão, compreensão e usos de elementos de uma cultura do escrito.

Ao buscarmos compreender modos e meios da constituição dos escritos, descobrimos algo mais a respeito das formas de pensar, das crenças, anseios e maneiras de se viver da sociedade em causa. No diálogo estabelecido entre disciplinas, fez-se possível o repensar do próprio conceito de escrita, além da compreensão de como se encontram organizadas investigações verticalizadas e criativas, as quais, de uma maneira ou de 
outra, preocuparam-se em abordar as relações que homens e mulheres estabeleceram com a escrita.

Nos espaços urbanos, palco em que fervilhavam ofícios e afazeres de natureza distinta, mesmo os sujeitos que não sabiam ler nem escrever viram-se convocados ao contato com a escrita. Nas frestas das relações de poder e com engenhosidade, as escolhas dos indivíduos foram, na longa duração, assumindo sonoridade e tornando o sistema mais permeável e flexível. Assim sendo, escravos, ex-escravos e mulheres, ou seja, setores em larga medida discriminados, puderam usar a escrita "via oralidade", e, desse modo, desvendar e afirmar seus posicionamentos sociais.

Recebido em março de 2014. Aprovado em abril de 2014. 